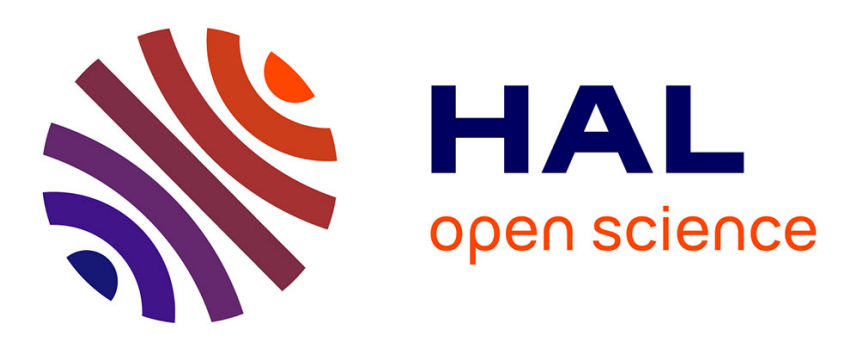

\title{
Kinetic Characterization by Respirometry of Volatile Organic Compound-Degrading Biofilms from Gas-Phase Biological Filters
}

\author{
A. Gonzalez Sanchez, L. Arellano Garcia, W. Bonilla Blancas, G. Baquerizo, \\ S. Hernandez, D. Gabriel, S. Revah
}

\section{To cite this version:}

A. Gonzalez Sanchez, L. Arellano Garcia, W. Bonilla Blancas, G. Baquerizo, S. Hernandez, et al.. Kinetic Characterization by Respirometry of Volatile Organic Compound-Degrading Biofilms from Gas-Phase Biological Filters. Industrial and engineering chemistry research, 2014, 53 (50), pp.1940519415. 10.1021/ie503327f . hal-01143012

\section{HAL Id: hal-01143012 https://hal.science/hal-01143012}

Submitted on 16 Apr 2015

HAL is a multi-disciplinary open access archive for the deposit and dissemination of scientific research documents, whether they are published or not. The documents may come from teaching and research institutions in France or abroad, or from public or private research centers.
L'archive ouverte pluridisciplinaire HAL, est destinée au dépôt et à la diffusion de documents scientifiques de niveau recherche, publiés ou non, émanant des établissements d'enseignement et de recherche français ou étrangers, des laboratoires publics ou privés. 


\title{
Kinetic characterization by respirometry of VOC-degrading biofilms from gas-phase biological filters
}

\author{
Armando González-Sánchez ${ }^{1,2}{ }^{*}$, Luis Arellano-García ${ }^{3}$, Wenceslao Bonilla-Blancas ${ }^{3}$, \\ ${ }^{6}$, Guillermo Baquerizo ${ }^{1,5}$, Sergio Hernández ${ }^{1}$, David Gabriel ${ }^{4}$, Sergio Revah ${ }^{1}$ \\ 1. Departamento de Procesos y Tecnología, Universidad Autónoma Metropolitana Cuajimalpa, Mexico City, \\ Mexico \\ 2. Instituto de Ingeniería, Universidad Nacional Autónoma de México (UNAM), Circuito Escolar, Ciudad \\ Universitaria, Mexico City, Mexico \\ 3. Posgrado en Ingeniería Química. Departamento de Ingeniería de Procesos e Hidráulica, Universidad Autónoma \\ Metropolitana Iztapalapa, Mexico City, Mexico \\ 4. Departament d'Enginyeria Química, Universitat Autònoma de Barcelona, Campus de Bellaterra, Barcelona, \\ Spain \\ 5. Irstea, UR MALY, Epure, Centre de Lyon-Villeurbanne, F-69626 Villeurbanne, France \\ 6. Tecnológico de Estudios Superiores de Ecatepec, Av. Tecnológico S/N, Col. Valle Anáhuac, 55210, Ecatepec \\ de Morelos, Mexico \\ *AGonzalezS@iingen.unam.mx
}

\begin{abstract}
A novel heterogeneous respirometer for in-situ assessment of the biological activity and mass transport phenomena of biofilm developed on packing materials of gas-phase biological filters is presented. The flexible respirometer configuration allows reproducing the operational features of biofilters and biotrickling filters to obtain reliable diagnoses of the bioreactor performance. A batchoperating mode was chosen for the biological assessment in which dynamic concentrations of oxygen, pollutant and carbon dioxide were on-line recorded and used to calibrate a mathematical model that considers the principal phenomena occurring in the respirometer. The maximum elimination capacity of two different packing materials colonized by sulfide-oxidizing bacteria and toluene-oxidizing fungal populations was estimated and compared with previously reported values. Additionally the rate controlling phenomena was analyzed using the biofilm effectiveness factor. The experimental system can be easily applied to pilot- and industrial-scale gas-phase biological filters when the kinetic expression of pollutant degradation is available.
\end{abstract}

Keywords: Biofiltration, respirometry, VOCs, mass transfer, dimethyl disulfide, toluene, bacteria, fungus, mathematical modeling

\section{INTRODUCTION}

Mitigating the noxious effects of air pollution is essential in promoting sustainable development. Anthropogenic VOCs emissions are severely affecting public health and ecosystems and some of these can further increase global warming ${ }^{1}$. In addition to known physicochemical methods, biological air treatment systems have been used to eliminate low concentrations of gaseous pollutants under ambient 
conditions. One of these biological techniques is biofiltration that consists in passing a polluted gas stream through a packed bed colonized by microorganisms, which transform the absorbed pollutants to new microorganisms and non-toxic substances ${ }^{2}$.

High performance of gas-phase biological filters, comprising both biofilters (BF) and biotrickling filters (BTF) may be reached with adequate control of nutrients and operation parameters of the process, although, in practice, performance may be difficult to maintain for long periods of time ${ }^{2}$. Optimum gas-phase biological filters operation is difficult to attain due to the limited knowledge of the interactions (chemical, biological and mass transport) occurring in the gas-phase of biological filter beds, besides the reduced number of variables that can be reliably measured in real-time. Mathematical modeling can be a useful tool to analyze the phenomena by simple equations ${ }^{2}$ expressed in terms of readily measured variables. However, simplifying the equations in a model must be supported by experimental evidence, which allows identifying key phenomena and providing consistent parameters to be included in the model. The use of a differential gas-phase biological filter operated as a closed-loop has shown to be a useful technique to evaluate the biological activity ${ }^{3}$ and to characterize mass transport in gas-phase biological filters 4,5 by preserving typical biofiltration conditions such as flow regimes. This procedure referred as heterogeneous respirometry might be deployed and adapted to evaluate biofilm and mass transport features in colonized packing samples by monitoring oxygen uptake rates.

Heterogeneous respirometry has advantages over the respiration measurement in free cells suspensions since preservation of biofilm morphology leads to a more realistic kinetics and mass transport examination. Drawbacks would be related with the heterogeneous colonization degree often encountered in pilot or full-scale gasphase biological filter packed beds, which would imply an extensive sampling and thorough respirometric assays in order to obtain representative results.

Heterogeneous respirometry should be carefully controlled to deal with these drawbacks and obtain reliable data. In this sense, the time-span of the assays should be short, (i.e. not exceeding $4 \mathrm{~h}$ ) to isolate only the biological activity with no net growth of biomass ${ }^{6}$. Also the emulation of external mass transport properties of a BTF by heterogeneous respirometry has to be guaranteed through the use of suitable liquid irrigation $4,5,7,8$, which in turn defines the packing wetting ratio, the latter identified as a determining factor for the removal of poorly water-soluble gases $^{9}$. In addition, some scale relations related to dead zones and wall effects for the liquid flow have to be considered. For minimizing wall effects on trickled beds the ratio between cross sectional area of column and the characteristic length of packing must be higher than ten ${ }^{10}$.

Once the heterogeneous respirometry has been carried out, results can be used to assess biofiltration performance by evaluating specific parameters such as the 
effectiveness biofilm factor $\eta^{11,12}$, which relates the biokinetics experimentally observed (through oxygen uptake rate) to the analogous calculated at interfacial or equilibrium conditions. Besides classical mass transfer coefficients (i.e. $K_{L} a$ or $K_{G} a$ ) other transport parameters could be formulated to compare the relative magnitude between mass transfer resistances ${ }^{12}$. In conjunction, these factors may lead to the identification of the controlling step in waste gas biofiltration, which may help in the formulation of new operation strategies to foster the gas treatment performance.

The aims of this study were to determine the limiting step during a biofiltration process through a novel mathematical model and to assess the effectiveness factor, which were provided with specific activity rates of biofilm and mass transport features evaluated through the heterogeneous respirometry technique. BF and BTF configurations were analyzed separately to examine the treatment of dimethyl disulfide (DMDS) and toluene emissions, respectively.

\section{MATERIALS AND METHODS}

\subsection{Heterogeneous Respirometer unit (HR)}

The HR unit consisted of a transparent PVC column ( $0.05 \mathrm{~m}$ I.D., $0.50 \mathrm{~m}$ length) with a packed bed height and volume of $0.26 \mathrm{~m}$ and $0.5 \mathrm{~L}$, respectively. Non-packed volumes of $0.25 \mathrm{~L}$ and $0.29 \mathrm{~L}$ were present at the top and bottom of the column, respectively, see Fig.1. The HR was properly installed to operate as a closed-loop either for gas and liquid streams, which were driven by independent pumps (Micropump 1-AA-MD Little Giant, Oklahoma, USA; Pump pack II, Analytical Instruments, California, USA). Liquid recirculation was optional to operate as a BTF. In all experiments reported the fluids linear velocities were chosen to be representative of the typical operation conditions in BFs and BTFs ${ }^{2}$. The HR was equipped with paramagnetic oxygen and carbon dioxide gas-phase analyzers (Model 1000 and 3400, California Analytical Instruments, USA), a polarographic sensor for dissolved $\mathrm{O}_{2}$ (Applisens, Applikon, The Netherlands) and a $\mathrm{pH}$ electrode (Sensorex, USA). The oxygen concentration in gas and liquid phases was recorded online every 5 seconds by connecting the aforementioned sensors to a LabJack $1 / O$ USB interface (LabJack Co., USA) and this in turn to a computer. 

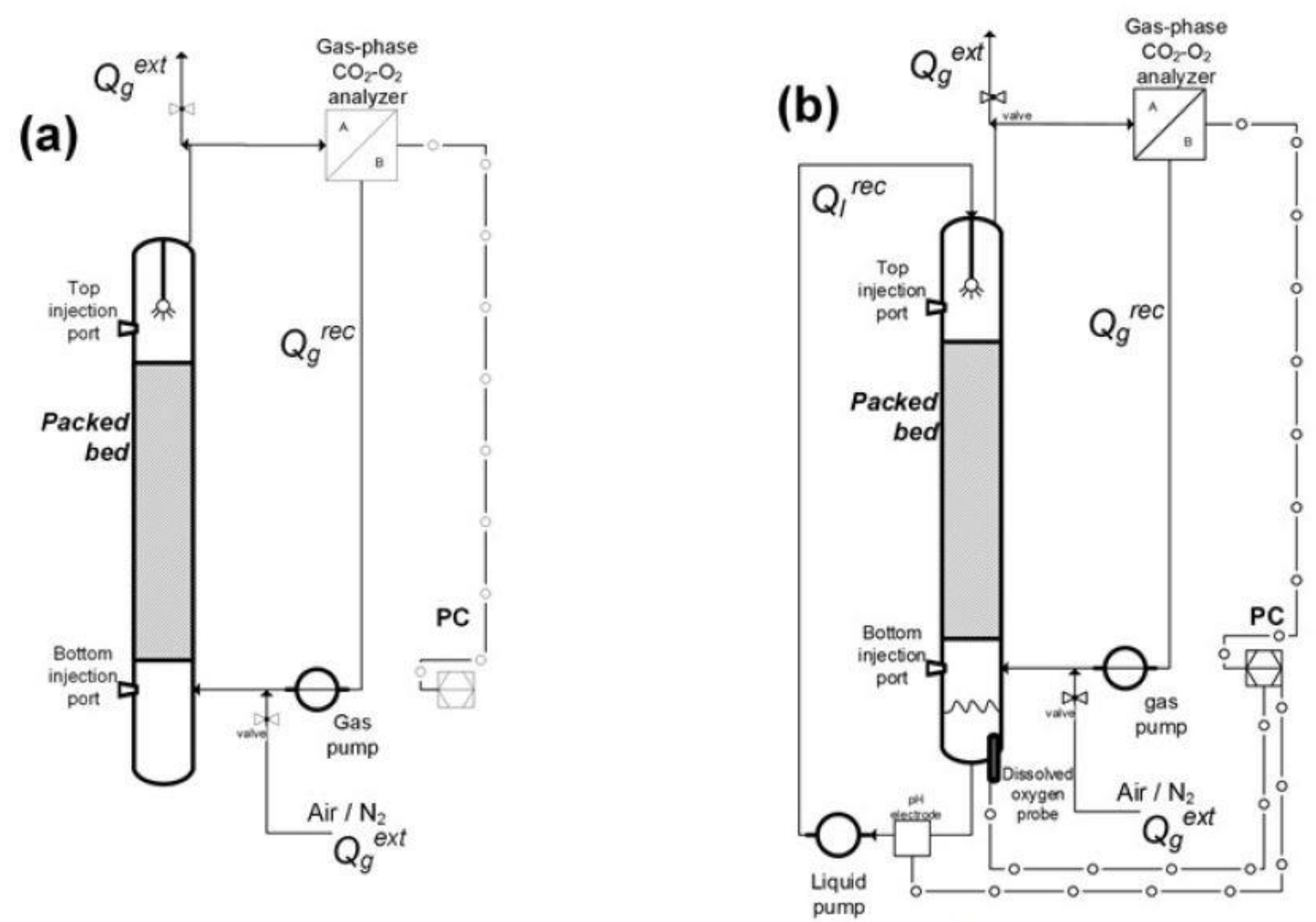

Figure 1. Heterogeneous Respirometer schematics. (a) BF configuration; (b) BTF configuration.

\subsection{Microorganisms and packing material}

\subsubsection{Alkaliphilic sulfide-oxidizing bacteria consortium (ASOC)}

Open-pore polyurethane foam (PUF) with specific area (a) of $600 \mathrm{~m}^{2} \mathrm{~m}^{-3}$, density of $35 \mathrm{~kg} \mathrm{~m}^{-3}$, and porosity of 0.97 (EDT, Eckenhaid-Eckental, Germany) was used as HR packing. The PUF average pore diameter was $0.31^{13} \mathrm{~cm}$ and this was considered as the characteristic nominal length of the packing. PUF cubes $(0.04 \mathrm{~m} \times 0.04 \mathrm{~m} \times$ $0.04 \mathrm{~m}$ ) colonized with an ASOC were withdrawn from an alkaline BTF, which had been fed with dimethyl disulfide (DMDS) for close to 6 months. Specific features of this source BTF and the composition of the alkaline mineral medium used can be found elsewhere ${ }^{14}, 15$. The PUF fragments were carefully cut without detaching biomass to form circular packing layers to precisely fit the cross sectional area of the $\mathrm{HR}$, thus way wall effects were diminished.

\subsubsection{Fungus adapted for toluene degradation}

The fungus Paecelomyces variotii CBS115145, adapted to toluene consumption, was obtained from a previous biofiltration study which details can be found elsewhere ${ }^{16,17}$. $P$ variotii was immobilized on PUF cubes under sterile conditions 
following the next procedure. First fungal growth was promoted by mixing $12 \mathrm{~g}$ of clean PUF cubes and $300 \mathrm{~mL}$ of a specific culture medium ${ }^{17}$ in two $1.0 \mathrm{~L}$ bottles. The initial $\mathrm{pH}$ of the mineral medium was 3.5. Twenty $\mathrm{mL}$ of a spore suspension with a concentration of $2 \times 10^{7}$ spores $\mathrm{mL}^{-1}$ were added to each bottle, which was sealed with screw caps equipped with Mininert Teflon valves (VICI, USA). A $20 \mu \mathrm{L}$ aliquot of liquid toluene ( $99.8 \%$, J.T. Baker, USA) was added every 3 days to each bottle as substrate. These batch cultures were kept in a rotary shaker at $150 \mathrm{rpm}$ and $30^{\circ} \mathrm{C}$. After two weeks, when a significant mycelia growth was observed the PUF cubes were also cut into circular layers, which served as packing for the HR column. This column was operated as lab-scale BF continuously supplied with $0.5 \mathrm{~L} \mathrm{~min}^{-1}$ of humidified air with a gaseous toluene concentration of around $6 \mathrm{~g} \mathrm{~m}^{-3}$ for two weeks. Afterwards the packed column was fitted to the HR (Fig. 1A) for a posterior evaluation by heterogeneous respirometry assays.

\subsection{External mass transfer characterization in the HR}

The overall liquid volumetric oxygen mass transfer coefficient $\left(K_{L} a_{g-l}\right)$ was evaluated for the HR operated as a BTF, either for clean and colonized PUF following the next procedure. First, the oxygen concentration in the gas and liquid phases was stabilized during 120 min by feeding a $0.12 \mathrm{~m}^{3} \mathrm{~h}^{-1}$ continuous fresh air stream and simultaneously recycling $210 \mathrm{~mL}$ of fresh alkaline mineral medium at a flow rate of $0.03 \mathrm{~m}^{3} \mathrm{~h}^{-1}$ flow, in order to have gas and liquid linear velocities of 89 and $14 \mathrm{~m} \mathrm{~h}^{-1}$, respectively. Then the air stream was exchanged by a pure nitrogen stream at the same flow rate for 1 minute. Afterwards, the evaluation of the oxygen external mass transfer rate, started by restoring the air feeding, with a flow rate of $0.07 \mathrm{~m}^{3} \mathrm{~h}^{-1}$ flow, for 10 min during which the oxygen concentration in both phases was recorded. Evaluation of the endogenous respiration of the attached biofilm (same procedure in section 2.4 , omitting the addition of any substrate) was done during biotic assays. The rate of oxygen accumulation besides the superficial area data and total volume of liquid inside the HR allowed calculating the $K_{L} a_{g-l}$ value for the specific conditions utilized in the respirometry experiments reported here.

For the HR operated as a BF, the overall gaseous volumetric oxygen mass transfer coefficient $\left(K_{G} a_{g-b}\right)$ was evaluated reproducing the same experimental procedure as described above for $K_{L} a_{g-l}$ but only measuring the oxygen concentration changes in the gas phase.

\subsection{Respirometry with HR operation as a BTF}

Before each respirometric test, the oxygen concentration was stabilized as performed on the external mass transfer characterization. The linear velocities used in the $K_{L} a_{g-l}$ determination were preserved. Each respirometric test was started by 
closing the HR inlet and outlet to operate as a closed-loop reactor. Under this substrate-free atmosphere, the immobilized ASOC endogenous respiration was assessed by recording the oxygen consumption in both gas and liquid for 60 minutes. Afterwards, the respiration related to microbial metabolism was evaluated by injecting a specific volume of a DMDS ( $99 \%$, SIGMA, USA) aqueous solution in the HR liquid reservoir, to attain an initial concentration of $0.75 \mathrm{mmol} \mathrm{L}^{-1}$, thus fostering a constant DMDS concentration in the biofilm surface. From this point on the liquid DMDS concentration was intermittently measured. For the HR operated as a BTF, the dynamic and total liquid hold-up were assessed according to TrejoAguilar et al., $2005^{18}$.

\subsection{Respirometry with HR operation as a BF}

For the $\mathrm{HR}$ operation as a $\mathrm{BF}$, a humidified airstream $\left(80 \%\right.$ relative humidity at $\left.25^{\circ} \mathrm{C}\right)$ at $0.072 \mathrm{~m}^{3} \mathrm{~h}^{-1}$ was passed through the HR packed bed for 8 hours to remove remaining traces of toluene and VOCs by-products. This period was selected to ensure a complete desorption without affecting the fungal biological activity, according to the reported performance of BFs colonized by fungal consortia ${ }^{19-21}$. Afterwards the HR inlet and outlet were closed keeping a gas loop linear velocity of $35.0 \mathrm{~m} \mathrm{~h}^{-1}$. In this condition, the fungal endogenous respiration was evaluated for 60 minutes. Toluene induced respiration started with the injection of a pulse of $7.2 \mu \mathrm{L}$ of liquid toluene $(100 \%$, JT Baker, USA) into the gas recycling stream, as slow as its evaporation allowed, for attaining an initial gaseous toluene concentration of $5.0 \mathrm{~g}$ $\mathrm{m}^{-3}$, which is a representative concentration for toluene biofiltration and below of reported inhibition levels ${ }^{16}$. At the same time, $\mathrm{CO}_{2}$ and $\mathrm{O}_{2}$ concentrations were continuously measured, while the toluene concentration was intermittently evaluated by manually sampling the gas phase.

\subsection{Analytical methods}

DMDS was quantified intermittently in the liquid phase as follows: using a syringe, an aliquot of $1.5 \mathrm{~mL}$ was extracted from the $\mathrm{HR}$ liquid reservoir; samples were placed in $5 \mathrm{~mL}$ glass vials (Agilent, USA), sealed with Mininert valves (VICl, USA) and maintained in an oven at $40^{\circ} \mathrm{C}$ for 1 hour. Afterwards $100 \mu \mathrm{L}$ from the gaseous headspace were extracted from each vial and injected in triplicate in a gas chromatograph (Hewlett Packard 5890, USA) equipped with a FPD detector and a capillary column (CP-PORABOND Q, $25 \mathrm{~m} \times 0.32 \mathrm{~mm} \times 5 \mu \mathrm{m}$, Varian, USA).

Toluene gaseous concentration was measured extracting $250 \mu \mathrm{L}$ gas samples from the HR to analyze them in triplicate in a gas chromatograph (Agilent Technologies, USA) equipped with a FID detector and a capillary column (AT-WAX $25 \mathrm{~m} \times 0.25 \mathrm{~mm} \times 0.2 \mu \mathrm{m}$, Alltech, USA). 


\subsection{Biomass quantification on the packing material}

After the respirometric assays, the biomass content in the packing material was evaluated. For the ASOC colonized PUF, the biofilm was removed by successive squeezing and rinsing the carrier cubes with mineral medium. Complete detachment of biomass was attained due to the PUF flexibility and the low biofilm resistance to mechanical stress. The biomass suspension thus obtained was centrifuged at 5000 $\mathrm{rpm}$ for $15 \mathrm{~min}$, the supernatant was discarded and the resulting pellet weight $\left(\mathrm{W}_{1}\right)$ and volume $\left(\mathrm{V}_{1}\right)$ were evaluated by taring the empty vial weight and measuring the pellet equivalent volume of water. This pellet was then dried at $50^{\circ} \mathrm{C}$ for 12 hours to determine the dry biofilm weight $\left(\mathrm{W}_{2}\right)$. The aforementioned conditions had been previously tested to verify that the total suspended solids in biofilms are properly determined.

For the fungal biomass, the dry weight corresponding to $W_{2}$, was assessed by detaching the mycelium from the PUF in the same way performed for the ASOC case. The obtained suspension was homogenized in a glass tissue grinder and afterwards the protein concentration was determined by using a protein determination kit (DC, BioRad, USA). The biomass dry weight content was calculated assuming a fungal protein content of $18 \%{ }^{17}$.

\subsubsection{Biomass properties calculations on the packing material}

An ASOC wet biofilm density of $1050 \mathrm{~kg} \mathrm{~m}^{-3}$ was calculated as $\rho_{\text {biofim }}=\mathrm{W}_{1} / \mathrm{V}_{1}$, while the dry-to-wet biomass weight ratio $(\omega)$, the fraction of wet biomass volume $\left(\varepsilon_{b}\right)$ in the bed and the dry-weight biomass content per bed volume $\left(X_{b}\right)$ were calculated from eqs 1 to 3 . The ASOC average biofilm thickness $(\delta)$ was evaluated using an optical microscope while a previously reported value ${ }^{20}$ was considered for the fungal biofilm. The biofilm shape was assumed as a uniform flat layer, which grows on a fraction area of the packing material $(\beta)$. The latter was computed from eq 4.

$$
\begin{aligned}
& \omega=\frac{W_{2}}{W_{1}} \\
& \varepsilon_{b}=\frac{V_{1}}{V_{\text {bed }}} \\
& X_{b}=\omega \cdot \rho_{\text {biofilm }} \cdot \varepsilon_{b} \\
& \beta=\frac{\varepsilon_{b}}{a \cdot \delta}
\end{aligned}
$$

\subsection{Comprehensive mathematical approach for the HR}

To describe the HR performance, a mathematical model based on mass balance 
equations under isothermal conditions was developed. Four phases (gas, liquid, wetted and non-wetted biofilm) were considered for simulating the HR as a BTF while only gas and non-wetted biofilm were considered for modeling the HR as a BF.

\subsubsection{Assumptions}

(1) Mass balance equations were based on general assumptions reported previously for gas-phase biofiltration process models $5,18,22-24$. Conversely to the usual biofiltration models, where the flow pattern of the bulk phases are modeled as plug-flow, in the HR it was assumed and ideal mixing of gas and liquid phases due to the batch operation mode with both phases recycling in a closed-loop.

(2) The common assumption made in lab-scale gas-phase biological filter models regarding uniform biofilm growth on packing material was discarded since the model was developed to be applied to packing materials obtained from different bioreactor scales (e.g. pilot and industrial), where this phenomenon is not observed. The available area for gas-liquid mass transfer was considered to be proportional to the wetted area fraction $(\alpha)$, which was calculated from the Onda correlation ${ }^{25}$. When $\beta>\alpha$ this indicates the existence of a non-wetted biofilm and its area was used to calculate the gasbiofilm mass transference (see Fig. 2).

Top view

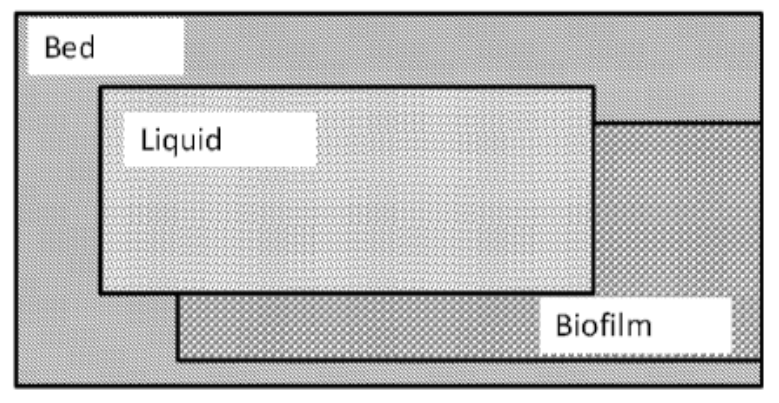

Side view

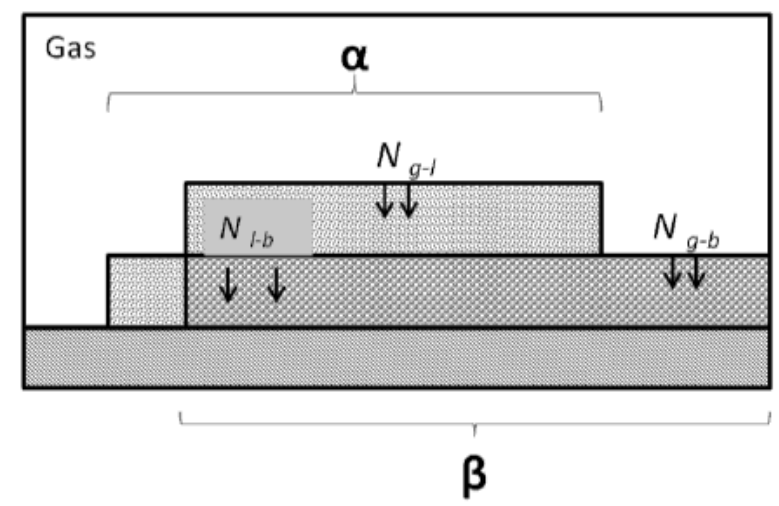

Figure 2. Diagram of the phases and fluxes considered in the mathematical model for the HR operated as a BTF. ( $\alpha$ ) Gas-liquid and ( $\beta$ ) liquid-biofilm fractional areas. For fungal biofiltration $\alpha=0$.

\subsubsection{Mass balance for the gas phase}

The equations to describe the dynamic mass balances of both oxygen and pollutant during respirometric assays are depicted in eqs 5 and 6 where the subscript $i$ refers to either gaseous oxygen or pollutant. Notice that free gas volume in the reservoir is 
considered to perform the mass balances. Mass fluxes are sated in eqs 11 to 13 according to assumptions listed in the previous section.

Gas phase in the packed bed

$\frac{d C_{g, i}}{d t}=\frac{Q_{g}^{e x t}}{V_{b e d} \cdot \varepsilon_{g}}\left(C_{g, i}^{i n}-C_{g, i}\right)+\frac{Q_{g}^{r e c}}{V_{b e d} \cdot \varepsilon_{g}}\left(C_{g, i}^{r e s}-C_{g, i}\right)-\frac{a_{g-l}}{\varepsilon_{g}} N_{g-l, i}-\frac{a_{g-b}}{\varepsilon_{g}} N_{g-b, i}$

Gas phase in the reservoirs

$\frac{d C_{g, t}^{r e s}}{d t}=\frac{Q_{g}^{e x t}+Q_{g}^{r e c}}{V_{g}^{r e s}}\left(C_{g, i}-C_{g, i}^{r e s}\right)$

Initial condition, at $\mathrm{t}=0$

$C_{g, i}=C_{g, i}^{r e s}=C_{g, i}^{0}$

Where

$a_{b}=\beta \cdot a$

$a_{g-l}=\alpha \cdot a$

$a_{g-b}=\left(a-a_{g-l}\right) \cdot \beta$

$\varepsilon_{g}=1-\varepsilon_{s}-\varepsilon_{l}-\varepsilon_{b}$

$N_{g-l, i}=K_{l, i}\left(\frac{C_{g, i}}{H e_{i}}-C_{l, i}\right)$

$N_{g-b, i}=\left.D_{e f f, i} \frac{d C_{b_{-} n w, i}}{d x}\right|_{x=0} \cong K_{B} \cdot \Delta C_{b_{-} n w, i}$

$N_{l-b, i}=\left.D_{e f f, i} \frac{d C_{b_{-} w, i}}{d x}\right|_{x=0} \cong K_{B} \cdot \Delta C_{b_{-} w, i}$

\subsubsection{Mass balance for the liquid phase}

Equations 14 to 17 depict the expressions defining mass balances for the liquid phase of the HR operated as a BTF, where the concentrations in the total liquid holdup $\left(V_{\mathrm{I}}\right)$ and in the liquid reservoir volume $\left(V_{l}\right.$ res $)$ were computed separately. 
Liquid in the packed bed (total liquid hold-up)

$$
\frac{d C_{l, i}}{d t}=\frac{Q_{l}^{r e c}}{\varepsilon_{l} \cdot V_{b e d}}\left(C_{l, i}^{r e s}-C_{l, i}\right)+\frac{a_{g-l}}{\varepsilon_{l}} N_{g-l, i}-\frac{a_{l-b}}{\varepsilon_{l}} N_{l-b, i}
$$

Liquid in the reservoir

$$
\frac{d C_{l, i}^{\text {res }}}{d t}=\frac{Q_{l}^{\text {rec }}}{V_{l}^{\text {res }}}\left(C_{l, i}-C_{l, i}^{\text {res }}\right)
$$

Initial condition, at $\mathrm{t}=0$

$$
C_{l, i}=C_{l, i}^{\text {res }}=C_{l, i}^{0}
$$

Where

$$
\begin{aligned}
& \varepsilon_{l}=\frac{V_{l}}{V_{b e d}} \\
& a_{l-b}=a_{g-l} \cdot \beta
\end{aligned}
$$

The $K_{L} a_{g-l}$ and $K_{G} a_{g-b}$ coefficients for oxygen were fitted by minimizing the difference between the experimental oxygen consumption data and the theoretical predictions calculated with eqs 5 and 14. Pollutant mass transfer coefficients from gas to liquid were then correlated as reported elsewhere 22 and shown in eq 18.

$$
k_{L, i}=k_{L, O_{2}} \sqrt{\frac{D_{e f f, i}}{D_{e f f, O_{2}}}}
$$

\subsubsection{Mass balance for the biofilm}

Equations 19 to 24 show the mass balances in the biofilm, describing both the dynamic oxygen and pollutant consumption rates as a function of biofilm depth. The equations 19 to 24 were used to calculate independently the concentrations in the wetted $\left(\mathrm{C}_{b_{-} w, i}\right)$ and non-wetted biofilm $\left(\mathrm{C}_{\mathrm{b} \_n w, i}\right)$, while corresponding boundary conditions were considered.

Biofilm in the packed bed 
$\frac{\partial C_{b, i}}{\partial t}=D_{e f f, i} \frac{\partial^{2} C_{b, i}}{\partial x^{2}}-r_{b, i}$

Initial conditions, at $\mathrm{t}=0$.

$$
\begin{array}{ll}
C_{b, O 2}=\frac{C_{g, O 2}^{0}}{H e_{O 2}} & \text { oxygen } \\
C_{b, \mathrm{P}}=0 & \text { pollutant }
\end{array}
$$

Boundary conditions for biofilm interface $(x=0)$

Wetted film $\quad N_{l-b, i}=\left.D_{e f f, i} \frac{d C_{b_{-} w, i}}{d x}\right|_{x=0}$

Non-wetted film $N_{g-b, i}=\left.D_{e f f, i} \frac{d C_{b_{-} n w, i}}{d x}\right|_{x=0}$

Boundary conditions at biofilm-support interface $(x=\delta)$

$$
\frac{\partial C_{b, i}}{\partial x}=0
$$

When the operation as a BTF was simulated, both wetted and non-wetted biofilm were included, while for the BF simulation only non-wetted biofilm was considered.

\subsubsection{Oxygen uptake stoichiometry}

Table 1 summarizes the stoichiometric equations considered in the model. Regarding the DMDS degradation by the ASOC, the conversion was considered to initiate (eq 25) to methanethiol (MT) as reported previously ${ }^{26}$. Afterwards, the fate of the MT was considered to be a function of exogenous $\mathrm{O}_{2}$ respiration (eqs 26, 30) based on earlier described evidences ${ }^{26}, 27$. These assumptions are valid under oxygen limiting conditions where elemental sulfur is predominantly produced and further oxidation to sulfate was not expected due to the short duration of respirometric assays.

The stoichiometric scheme for toluene oxidation catalyzed by $P$. variotii was described previously ${ }^{17}$ and is depicted in eqs 27 and 28 , where the presence of the benzyl alcohol $(\mathrm{BOH})$ controls the production of $\mathrm{CO}_{2}$.

The endogenous $\mathrm{O}_{2}$ respiration was represented by eq 29 for both HR configurations. 
Table 1. Stoichiometry and kinetic expressions of the respirometry

\begin{tabular}{llll}
\hline Substrate & Stoichiometry & $\begin{array}{l}\text { Characteristic } \\
\text { kinetic constant }\end{array}$ & $\mathrm{Eq}$ \\
\hline DMDS & $\mathrm{CH}_{3} \mathrm{SSCH}_{3} \rightarrow 2 \mathrm{CH}_{3} \mathrm{SH}$ & $R_{\max }$ & $(25)$ \\
Methanethiol & $\mathrm{CH}_{3} \mathrm{SH}+\mathrm{OH}^{-}+0.75 \mathrm{O}_{2} \rightarrow \mathrm{S}^{0}+\mathrm{CH}_{2} \mathrm{O}+$ OURmax & \\
& $1.5 \mathrm{H}_{2} \mathrm{O}$ & & \\
Toluene & $\mathrm{C}_{7} \mathrm{H}_{8}+0.245 \mathrm{O}_{2} \rightarrow \mathrm{C}_{6} \mathrm{H}_{5} \mathrm{CH}_{2} \mathrm{OH}$ & OUR & \\
Benzyl alcohol & $\mathrm{C}_{6} \mathrm{H}_{5} \mathrm{CH}_{2} \mathrm{OH}+5.75 \mathrm{O}_{2} \rightarrow 4.6 \mathrm{CO}_{2}$ & OUR & $(27)$ \\
Endogenous & Biomass $+\mathrm{O}_{2} \rightarrow \mathrm{CO}_{2}$ & OUR \\
respiration & & & $(28)$ \\
\hline
\end{tabular}

\subsubsection{Microbial kinetics}

Table 2 portrays the biological kinetic equations utilized in the HR simulation, which are expressed in terms of the maximum Oxygen Uptake Rate $\left(O \cup R_{\max }\right)$ except in the case of DMDS conversion. According to eq 25, the conversion step to methanethiol does not imply any oxygen consumption (eq 33). This step was considered to be inhibited by substrate and byproduct ${ }^{28}$. Kinetic parameters were taken from previous reports ${ }^{14,16,17,29}$ (see supporting information Table S1) and were used as reference during the estimation of the intrinsic kinetic parameters of biofilm, which were equally applied for modeling wetted and non-wetted biofilm.

Table 2. Kinetic models for reactions considered to be occurring inside the biofilm

\begin{tabular}{lll}
\hline Substrate & Specific oxygen consumption rate & $\mathrm{Eq}$ \\
\hline Methanethiol or & $r_{b, O_{2}}=O U R_{\max }\left(\frac{C_{b, O 2}}{K_{s, O 2}+C_{b, O 2}}\right)\left(\frac{C_{b, P}}{K_{s, P}+C_{b, P}}\right)$ \\
$r_{b, O_{2}}=\alpha \cdot r_{b_{-} w, O_{2}}+(1-\alpha) \cdot r_{b_{-} n w, O_{2}}=\frac{q_{O_{2}} \cdot X_{b}}{\varepsilon_{b}}$ & \\
& $r_{b, P}=\frac{r_{b, O_{2}}}{Y_{O_{2} / P}}=\frac{q_{P} \cdot X_{b}}{\varepsilon_{b}}$
\end{tabular}




\begin{tabular}{lll}
\hline Benzyl alcohol & $r_{b, O_{2}}^{*}=O U R_{\max } \frac{C_{b, B O H}}{K_{s, B O H}+C_{b, B O H}}$ & $(34)$ \\
\hline $\begin{array}{l}\text { Endogenous } \\
\text { respiration }\end{array}$ & $r_{b, O_{2}}^{\text {end }}=O U R^{\text {end }}$ & \\
\hline
\end{tabular}

Where $Y_{\mathrm{O} / \mathrm{P}}$ is the specific oxygen to pollutant stoichiometric coefficients $\left(\mathrm{g} \mathrm{g} \mathrm{g}^{-1}\right)$ specified in eqs 26 and $27\left(\mathrm{~mol} \mathrm{~mol}^{-1}\right)$. The same kinetics was considered for either the wetted and non-wetted biofilm.

\subsubsection{Theoretical prediction of gas treatment performance}

Theoretical pollutant elimination capacities (EC) (gpollutant $\mathrm{m}^{-3}$ bed $\mathrm{h}^{-3}$ ) were estimated from the corresponding oxygen uptake rates, stoichiometry and kinetics as stated in eq 36 , which considered the contribution of wetted and non-wetted biofilm.

$$
E C_{\text {Polluntant }}=\left[\left(r_{b_{-} w, \mathrm{P}} \cdot a_{l-b}\right)+\left(r_{b-n w, \mathrm{P}} \cdot a_{g-b}\right)\right] \cdot \delta
$$

\subsection{Assessment of the rate-controlling phenomena during the biofilm respirometry}

The isothermal effectiveness factor $\eta$ concept for a slab geometry was applied for the attached biofilm in the gas-phase biological filters packing bed. The dissolved oxygen was assumed as the rate-controlling component of bioactivity ${ }^{30}$. The biofilm and overall $\eta$ were defined by eqs 37 and 38 as the quotient of observed OUR in whole biofilm with respect to either the OUR evaluated under superficial conditions ( $\eta$ biofilm) or under physical aqueous equilibrium conditions with the bulk gas phase ( $\eta$ overall) respectively. The evaluation of OUR under superficial conditions is based on the fact that the oxygen and pollutant concentrations on the external surface of the biofilm are influenced by the external mass transport $\left(K_{L} a_{g-l}\right.$ and/or $\left.K_{G} a_{g-b}\right)$. In the evaluation of OUR under physical aqueous equilibrium conditions, insignificant external resistance to mass transport is assumed; then the calculation uses dissolved oxygen and pollutant concentrations on the external surface of the biofilm in equilibrium with the respective component in the gas bulk phase. The mathematical model can evaluate the respective $\eta$ every time.

$$
\begin{aligned}
& \eta_{\text {biofilm }}=\frac{O U R_{\text {observed }}}{O U R_{\text {superficial }}}=\frac{r_{b, O_{2}}}{\left.r_{b, O_{2}}\right|_{\text {superficial }}} \\
& \eta_{\text {overall }}=\frac{O U R_{\text {observed }}}{O U R_{\text {equilibrium_phases }}}=\frac{r_{b, O_{2}}}{\left.r_{b, O_{2}}\right|_{\text {equilibrium_phases }}}
\end{aligned}
$$


Following an approximation reported by several authors Fogler $2005^{31}$, Andrews $1988^{30}$ and Bailey and Ollis $1976^{32}$ and valid for various reaction kinetic orders, a criteria based on the observed OUR was used for identification the rate controlling phenomena during the respirometric assay. When $\eta$ biofilm $>0.9$ the biofilm is considered to be fully active otherwise the penetration of oxygen inside the biofilm is becoming incomplete due to diffusional limitation ${ }^{31}$, which is completely limited at $\eta$ biofilm $<0.5$. Only for the fully active biofilm case, the overall effectiveness factor must be evaluated, where for $\eta_{\text {overall }}>0.75$ the global biofiltration process is not limited by external mass transport. Since mass transport (external and diffusional) and the bioreaction mechanisms were independently assessed from the mathematical model, biokinetic parameters estimated here (i.e. OUR $R_{\max }, R_{\max }$, etc.) can be considered as "intrinsic parameters", which characterize the biological activity of the microorganisms in the biofilm.

\subsection{Model solution and parameters estimation}

The set of partial differential equations was discretized in 10 points along the biofilm thickness. The complete set of ordinary differential equations was solved using Berkeley Madonna 8.3.18. A low, variable-order non-stiff integration method was used to solve mathematical equations after testing different integration methods provided by the modeling software. Initial conditions for all state variables are defined above.

Parameter estimation by fitting the model to experimental data and model simulations were also performed in Berkeley Madonna 8.3.18. For the case of partial differential equations (mass balances in biofilm), these were converted to six $(N=6)$ discrete ordinary differential equations as described elsewhere ${ }^{33}$. The gaseous $\mathrm{O}_{2}$, dissolved $\mathrm{O}_{2}$, the pollutant and $\mathrm{CO}_{2}$ (if applicable) concentration profiles generated from respirometric experiments simulation were used to calibrate the mathematical model. Parameter estimation was performed by minimizing the error between model predictions and measured variables by the least square method. A statistical analysis based on paired t-Student tests at a $5 \%$ level of significance were performed for the corresponding compounds concentration, for quantifying the agreement between results predicted by the model using the optimized kinetic parameters and the experimental data. A compilation of the parameters utilized in the model is included in supporting information (table S2), indicating if the parameter was experimentally determined, model-estimated or selected from the literature. A sensitivity analysis of the mathematical model was also executed (Figure S3). 


\section{RESULTS AND DISCUSSION}

\subsection{Assessment of the external mass transfer coefficients}

Oxygen $K_{L} a_{g-l}$ and $K_{G} a_{g-b}$ determined for non-colonized and colonized packing are shown in table 3 as a function of gas and liquid linear velocities. Results are in agreement with values reported by other authors 4,25 . Both gas and liquid linear velocities applied here were selected as representative of those used during the regular operation of a pilot-scale $\mathrm{BTF}^{2}$.

Table 3. Oxygen $K_{L} a_{g-l}$ and $K_{G} a_{g-b}$ values determined for polyurethane foam (PUF) in $\mathrm{HR}$ experiments and theoretical values calculated from the literature.

\begin{tabular}{llllll}
\hline PUF condition & $\begin{array}{l}U_{L z} \\
\left(\mathrm{~m} \mathrm{~h}^{-1}\right)\end{array}$ & $\begin{array}{l}U_{G z} \\
\left(\mathrm{~m} \mathrm{~h}^{-1}\right)\end{array}$ & $\begin{array}{l}K_{L} a_{g-l}\left(\mathrm{~h}^{-1}\right) \\
\text { exp. }\end{array}$ & $\begin{array}{l}K_{L} a_{g-l}\left(\mathrm{~h}^{-1}\right) \\
\text { theoretical }\end{array}$ & $\begin{array}{l}K_{G} a_{g-b}\left(\mathrm{~h}^{-1}\right) \\
\text { theoretical }\end{array}$ \\
\hline Clean & 14.8 & 89.0 & 14.4 & 19.1 & N.A. \\
$\begin{array}{l}\text { ASOC } \\
\text { colonized(a) }\end{array}$ & 14.8 & 89.0 & 26.4 & 33.4 & 17.5 \\
$\begin{array}{l}\text { Fungal } \\
\text { colonized }\end{array}$ & N.A. & 35.0 & N.A. & N.A. & 186 \\
\hline
\end{tabular}

(a) ASOC attached biomass on PUF 15.7 kgdrybiomass $\mathrm{mbed}^{-3}$

(b) Fungal attached biomass on PUF 0.6 kgdrybiomass $\mathrm{mbed}^{-3}$

$U_{L z}, U_{G z}$ : liquid and gas linear velocities respectively

NA: not applicable

For the experimental conditions reported here, $K_{L} a_{g-l}$ for colonized packing were in average $90 \%$ greater than the computed for the non-colonized PUF. This behavior could be explained by an increase in the interfacial area (see Fig. 2a) due to biofilm growth $^{13}$. Also it is known that biofilm heterogeneities interact with liquid flow to produce turbulence at local scale which in turn could enhance gaseous pollutants absorption by decreasing the thickness of the stagnant layer of the liquid phase ${ }^{34}$.

\subsection{Respirometry of ASOC colonized bed using the BTF configuration}

Figure 3 shows the performance of a selected respirometric test during the DMDS induced respiration. The linear velocities for gas and liquid in each case are shown in table 3 . Time $t=0$ corresponds to the addition of a pulse of DMDS. Oxygen concentration changes in gas and liquid phases were induced by the biological respiration. The solid line represents the model best-fit predictions after estimating the corresponding parameters showed in supporting Information table S3. 
Comparison between OURS determined in this study with other reported results is not a straightforward procedure since the biomass content of lab-scale or pilot BTFs is seldom examined. In addition, biomass colonization is often heterogeneous along the packed bed height, which impacts on operational parameters and performance ${ }^{13}$. However, the intrinsic kinetic parameters in table $S 3$ could be taken as reference values for operation or simulation of a BTF treating similar VOC.
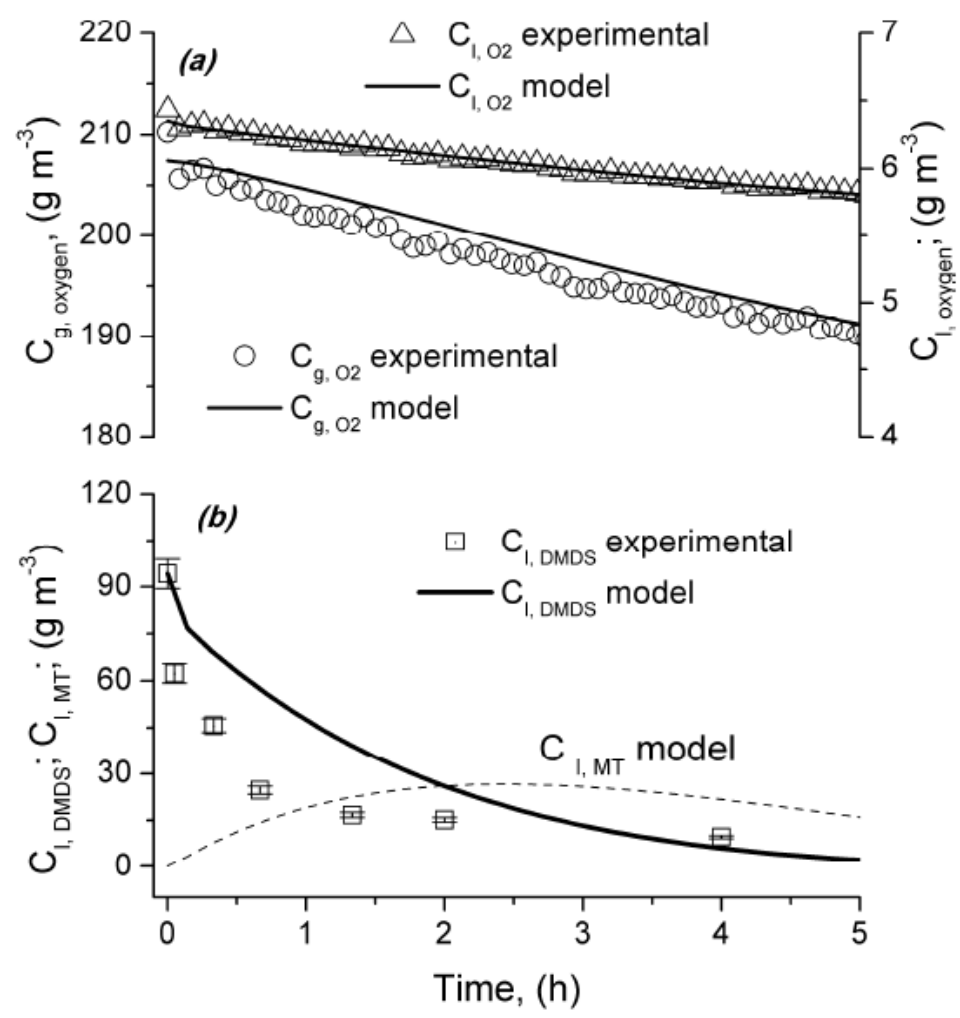

Figure 3. Batch respirometry performance using the HR as a BTF, with DMDS as substrate and the ASOC colonized polyurethane foam as packing. Linear velocities for gas and liquid were $89 \mathrm{~m} \mathrm{~h}^{-1}$ and $14.8 \mathrm{~m} \mathrm{~h}^{-1}$ respectively. (a) Gaseous and dissolved oxygen profiles; (b) Dissolved DMDS profile.

A paired sample t-Student $(\alpha=0.05)$ test between experimental and model predicted concentrations was carried out, which indicated that no significant differences existed for gaseous and dissolved oxygen. However, significant differences between the simulated and the measured DMDS liquid concentration were found. The DMDS degradation pathway (eqs 25 and 26) proposed methanethiol and elemental sulfur as intermediaries, by uncoupling the DMDS consumption from oxygen, which 
resulted in an more acceptable fitting of the computed concentration profiles to the experimental concentrations (see Figure $3 a$ and $3 b$ ) compared with considering only the DMDS degradation coupled to oxygen consumption (data not shown). In our work, methanethiol defined the oxygen consumption leading to sulfur accumulation (not measured) during the time considered for respirometry assays (see Figure 3 ).

DMDS is present in both dissolved and gaseous forms in the HR as well as inside the biofilm (see simulated profiles Figure S1 Supporting Information). In this case, the model predicts that the wetted and non-wetted biofilm participate in substrate degradation. A relevant modeling result is that the non-wetted biofilm showed a faster mass transfer rate and then 1.7 times more oxygen consumption compared to the wetted biofilm (see Figure $4 \mathrm{~b}$ ). In the non-wetted biofilm the transport resistance of the liquid film is negligible, thus the oxygen and gaseous DMDS absorption is favored and this, in turn, may promote higher bioreaction rates in comparison to the wetted biofilm.

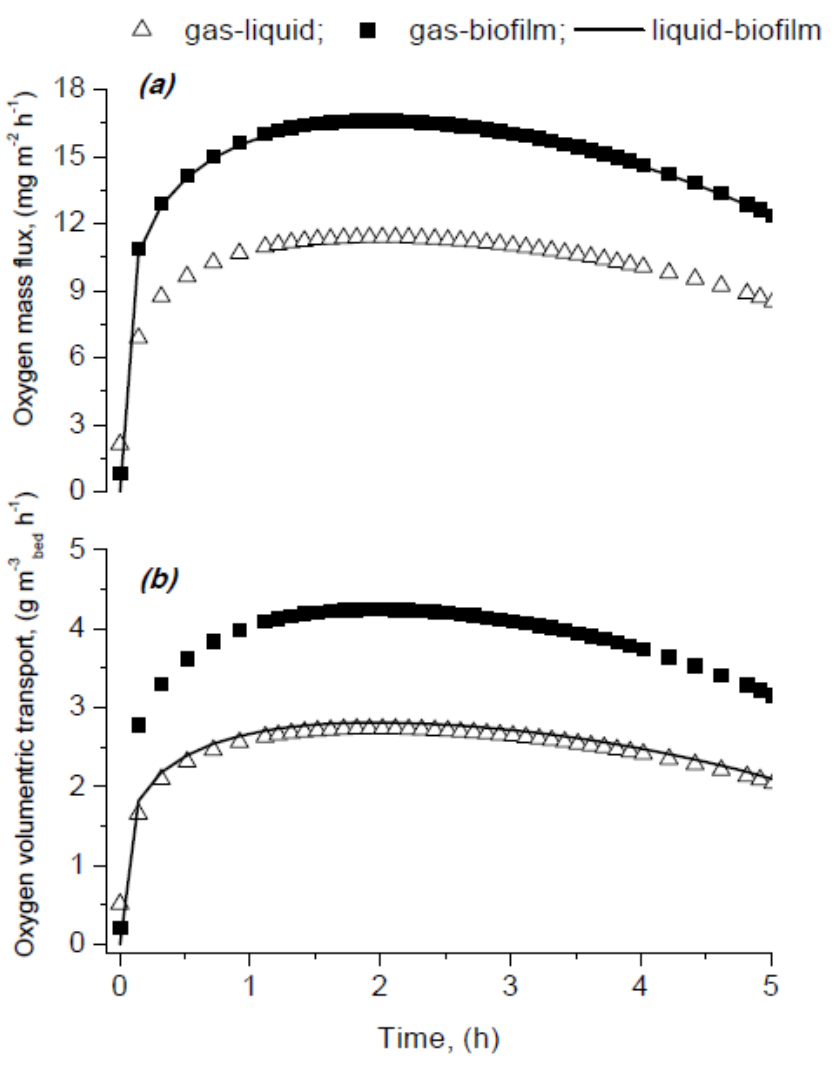

Figure 4. Fluxes (a) and volumetric mass transfer rates (b) through the three interfaces considered in the HR model, operated as BTF for the consumption of DMDS. 
Oxygen is a poorly soluble compound in aqueous solutions and often a rate limiting compound during aerobic biofiltration of VOCs. In consequence, the role of oxygen mass transfer in the three interfaces considered in the model was analyzed (figure 4). In terms of mass flux, the liquid-biofilm and gas-biofilm interfaces contributed equally to the global flux, while the gas-liquid interface yields the slowest flux. The latter confirms that the liquid film is a significant resistance to the mass transport of poorly soluble gaseous compounds to aqueous solutions. Whereas in terms of volumetric mass transfer rates, the major contribution was reached through the gasbiofilm interface because of the highest $a_{g-b}\left(255.6 \mathrm{~m}^{2} \mathrm{~m}^{-3}\right)$, while gas-liquid $\left(a_{g-l}=\right.$ $\left.240 \mathrm{~m}^{2} \mathrm{~m}^{-3}\right)$ and liquid-biofilm $\left(a_{l-b}=170.4 \mathrm{~m}^{2} \mathrm{~m}^{-3}\right)$ interfaces contributed less to the global mass transference. The results offer the possibility to redistribute the areas of interfaces by manipulating the operating conditions in the BTF source of the tested sample of packing bed and then improving the oxygen global mass transfer rates and, consequently, the performance of the BTF.

Table 4. Comparison of performance parameters for bacterial and fungal biomass deployed in DMDS and toluene biofiltration respectively.

\begin{tabular}{|c|c|c|c|c|}
\hline Microorganism & Parameter & Value & Units & Reference \\
\hline DDB & $\mathrm{qO}_{2}$ (immobilized) & 0.07 & $\mathrm{nmolO}_{2}\left(\text { g }_{\text {biomass }} \min \right)^{-1}$ & this paper \\
\hline DDB & $\mathrm{qO}_{2}$ (Suspension) & $5.6 \times 10^{3}-1.8 \times 10^{5}$ & $\mathrm{nmolO}_{2}\left(\text { g }_{\text {biomass }} \min \right)^{-1}$ & $14,35,36$ \\
\hline DDB & $\mathrm{EC}_{\max }$ & 82 & GDMDS $\mathrm{m}^{-3}$ bed $h^{-1}$ & this paper \\
\hline DDB & $E C_{\max }$ & $15-53$ & gDMDS $\mathrm{m}^{-3}$ bed $h^{-1}$ & $14,37,38$ \\
\hline TDF & $\mathrm{qO}_{2}$ (immobilized) & 5.61 & $\mathrm{nmolO}_{2}\left(\text { g biomass }_{\min }\right)^{-1}$ & this paper \\
\hline TDF & $\mathrm{qO}_{2}$ (Suspension) & $1.0 \times 10^{4}-1.6 \times 10^{5}$ & $\mathrm{nmolO}_{2}\left(\text { g }_{\text {biomass }} \min \right)^{-1}$ & 17,39 \\
\hline TDF & $\mathrm{EC}_{\max }$ & 15.8 & $\mathrm{~g}_{\text {Toluene }} \mathrm{m}^{-3}$ bed $\mathrm{h}^{-1}$ & this paper \\
\hline TDF & $\mathrm{EC}_{\max }$ & $100-595$ & $\mathrm{~g}_{\text {Toluene }} \mathrm{m}^{-3}$ bed $\mathrm{h}^{-1}$ & 17,40 \\
\hline
\end{tabular}

DDB: DMDS degrading bacteria; TDF: Toluene degrading fungus.

From data depicted in table 4 it is clear that the specific respiration rates $\left(\mathrm{qO}_{2}\right)$ evaluated for attached biomass are evidently lower than the analogous obtained previously by other authors in free-cell suspensions. The main difference arise from the technique utilized to evaluate the microbial respiration, which in biomass suspensions conventional respirometry minimizes mass transfer resistances for the substrate bioavailability as well as for the excretion of inhibitory by-products. While determination for attached biomass the HR preserves the main features and phenomena occurring in the absorption process that might be present in pilot and 
full-scale biological gas treatment applications. In this case, the heterogeneous determination of biological activity may lead to more realistic predictions of performance and limitations of the process. In terms of pollutant gas-phase biofiltration performance, the corresponding ECs were computed from the model for both BTF and BF. Recent studies described ECs as high as 53 and 32 gDMDs m$^{-3} \mathrm{~h}^{-}$ ${ }^{1}$ with a RE of $94 \%$ for BTFs inoculated with neutrophilic bacteria ${ }^{37,}{ }^{38}$ while our model predicted higher EC for the piece of sampling bed tested, probably due to the large amount of alkaliphilic biofilm attached $\left(15.65 \mathrm{~kg} \mathrm{~m}^{-3}\right.$ bed $)$.

\subsection{Respirometry of the fungal colonized bed using a BF configuration}

Figure 5 shows the performance of the respirometric test after addition of a toluene pulse $(t=0)$. In this batch respirometry, toluene elimination induced consumption of the gaseous oxygen and consequential production of carbon dioxide. Furthermore, the model predicted an initial formation of a mixture of $\mathrm{CO}_{2}$ and benzyl alcohol $(\mathrm{BOH})$ as was reported previously ${ }^{17}$. While the model adequately represents toluene uptake; it is not as suitable to describe the concomitant $\mathrm{O}_{2}$ uptake. This suggest the necessity to uncouple toluene uptake and mineralization processes, here with a single intermediary $(\mathrm{BOH})$ production, in any case additional efforts should made to better explain the mechanism of toluene uptake by fungi. An additional explanation of the inadequate description of oxygen consumption might be referred to an overestimated endogenous activity (OUR end).
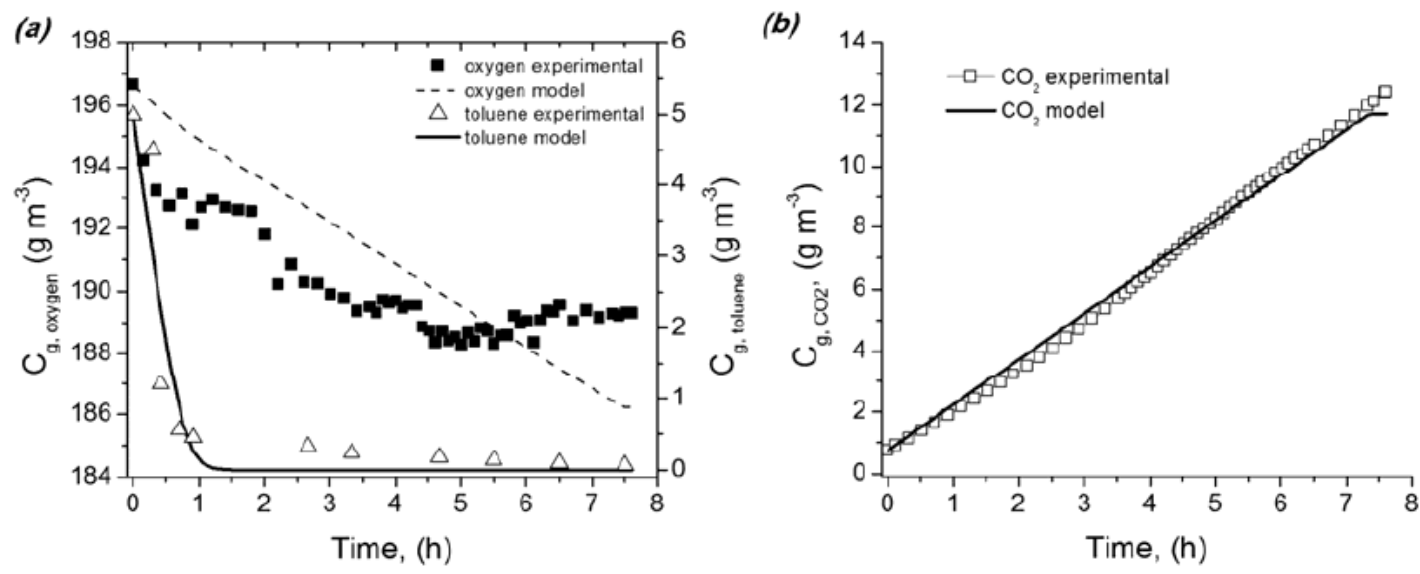

Figure 5. Batch respirometry performance using the HR as a BF, with toluene as substrate and the fungal colonized polyurethane foam as packing. Linear velocity for gas was $35 \mathrm{~m} \mathrm{~h}^{-1}$. (a) Gaseous oxygen and toluene profiles; (b) Gaseous carbon dioxide profile.

The global carbon mass balance (Figure S2, Supporting Information) during the 
respirometry assay showed that an important fraction of the unaccounted carbon $(>98 \%)$ was not detected, therefore $C$ was probably assimilated as fungal biomass or transformed into other soluble intermediates ${ }^{41}$ (not included in the model).

Table S3 shows the biokinetic parameters for the fungal colonized PUF computed by the model, after the best fitting procedure. Table 4 shows the EC of toluene estimated from oxygen uptake rate was consistent with values found in the literature for fungal $\mathrm{BFs}^{17}$, probably due to the more complex and robust performance than bacteria. A biofiltration system inoculated with the mold Paecilomyces variotii CBS115145 showed toluene EC of around $250 \mathrm{~g} \mathrm{~m}^{-3} \mathrm{~h}^{-1} 17$, while other authors reported $270 \mathrm{~g} \mathrm{~m}^{-3} \mathrm{~h}^{-1}$ with Exophiala lecanii-corni21. In this aerobic fungal toluene biofiltration process, high removal efficiencies due to the high biomass content on the bed can be expected. Nevertheless, a drastic reduction in the EC could occur because of an excessive growth, thus producing a reduction in the real gas residence time as well as a high pressure drop ${ }^{2}$.

\subsection{The rate controlling phenomenon in biofilm respirometry}

For the BTF configuration, figure 6 shows the evaluation of the effectiveness factor for the biofilm ( $\eta$ biofilm) by means of eq 37 . During the simulation of the DMDS respirometry assay, the $\eta$ biofilm showed values close to 1.0 indicating that under the conditions tested ( $\mathrm{C}_{\text {pollutant }}>>\mathrm{C}_{\mathrm{O}}$ ) the global process was controlled by the bioreaction. Results are consistent with a sensitivity analysis performed (Figure S3, Supporting Information). Biokinetic parameter variation ( $\pm 10 \%$ of the mean) modified the $\mathrm{EC}_{\max }$ predicted by the model. However, the $\mathrm{EC}_{\max }$ predicted remained constant when mass transport parameters were varied. Such limitation can be overtaken by increasing the biomass concentration either on the packing bed or in suspension. Of course, it would be expected this trend to have an optimum value. Afterwards the biomass accumulation might produce undesirable effects such as an elevated pressure drop, dead zones and channeling in the colonized packing ${ }^{13}$.

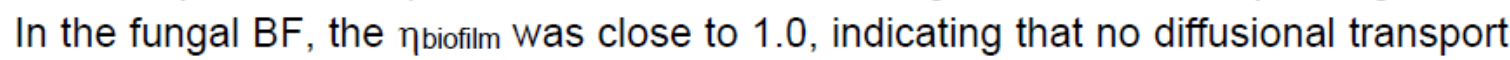
existed. In this situation, the ECs could be improved by increasing the fungal biomass content. In case of external mass transport limitation ( could be improved with higher linear velocity of the fluids, either by increasing the gas flow rate or by reducing the transversal area of the BF. 

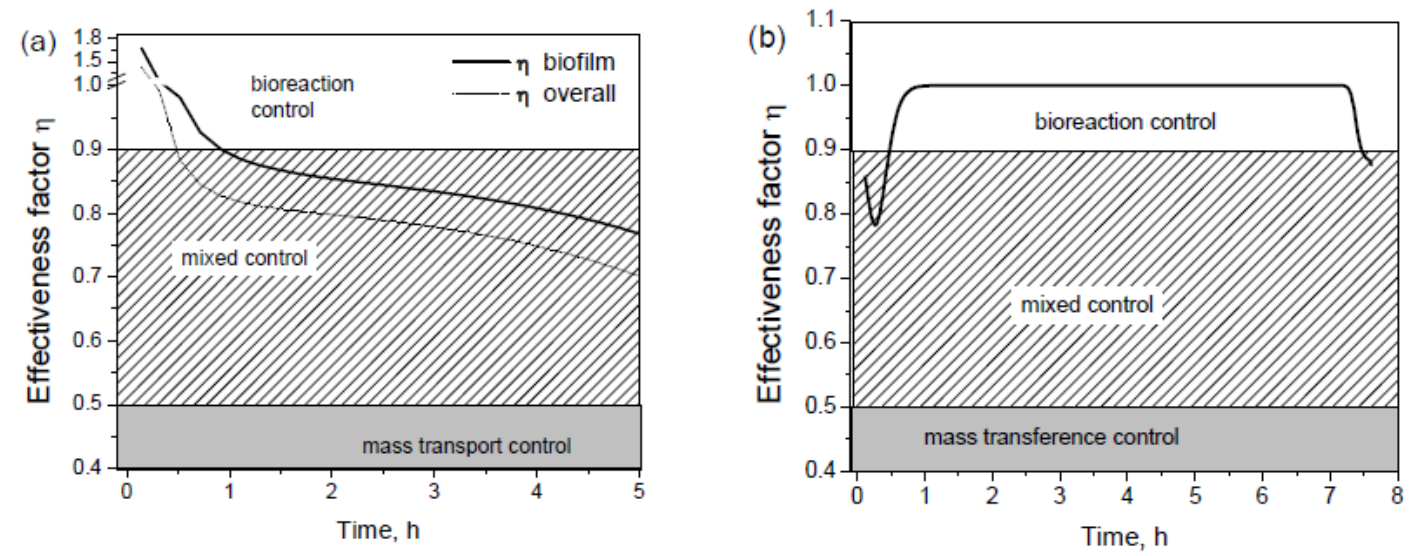

Figure 6. Estimated biofilm effectiveness factor during the simulated respirometry assays for (a) DMDS and (b) toluene elimination. Criteria for regime control from $31,30,32$.

Initial values for the effectiveness factor above 1.0 were predicted since DMDS and MT were considered as inhibitory of DMDS degradation (eq 33). At the beginning of the HR assay, no inhibitory sulfide concentrations were reached in the biofilm (see simulated profiles in Figure S1). However, afterwards pollutant was transferred to the inner layers of the biofilm generating an increment of both pollutant and byproducts concentration and thus leading to operate under inhibitory conditions. Later the inhibition decreased due to biological consumption. Nevertheless, since DMDS was consumed, the external transport could condition the efficiency of the treatment as shown in figure 6 , after $1 \mathrm{~h}$ (grey area).

For the case of fungal biofilm (see simulated profiles in Figure S4), the effectiveness factor also indicated complete activity in the whole biofilm. Then, only by promoting biomass growth the toluene removal capacity could be improved.

Under prolonged pollutant removal in a BF or BTF, excessive biomass accumulation hinders the transfer of both oxygen and nutrients to the deeper biofilm layers, reducing the biomass surface area and increasing the pressure drop until complete clogging ${ }^{40}$.

Predictions regarding the $\eta$ biofilm and $\eta_{\text {overall }}$ obtained through the heterogeneous respirometry methodology are valuable in terms of experimental simplicity implying only oxygen concentrations measuring in the assays. Furthermore, model predictions are qualitatively in agreement with Lobo et al. (1999) ${ }^{12}$ who established a general criterion to identify the rate-limiting step in BTFs performance for a first order kinetic reaction. According to Lobo et al. (1999) ${ }^{12}$ if the limiting substrate liquid concentration is close to 0 , the rate-controlling step would be mass transfer at the gas-liquid interface; whereas if it is close to the value in equilibrium with the gas phase, the controlling step would be the phenomena occurring in the biofilm. The 
heterogeneous respirometry technique would allow evaluating the performance of a full-scale gas-phase biological filter from a sample of packing material if assays are performed under the same operational conditions. If a convenient sampling strategy is considered in the source gas-phase biological filter (e.g. sampling at the inlet, outlet and middle sections along the bed height).

\section{CONCLUSIONS.}

Heterogeneous respirometry represents an efficient and reliable tool for the characterization of gas-phase biological filters. This technique was applied to perform a comprehensive diagnosis of two lab-scale gas-phase biological filters colonized by ASOC and fungal consortiums removing DMDS and toluene respectively. The accurate assessment of mass transport and kinetics in the biofilm complements the model description and provides a more realistic analysis of the biofiltration process by means of the effectiveness factor assessment. The flexible configuration of HR allows applying this diagnostic procedure to gas-phase bioreactors operating at different scales (lab-, pilot- and industrial scale), provided the proper kinetic expression of pollutant degradation is available. Furthermore, the proposed technique might be used as a reference to characterize other heterogeneous biological processes by adding the corresponding gas and/or dissolved sensor to the bulk phases in the HR.

\section{ACKNOWLEDGMENTS}

The financial support of the Mexican National Council on Science and TechnologyCONACYT (Basic Science Projects 166451 and 168288). We also acknowledge and appreciate the comments of the anonymous reviewers.

\section{SUPPORTING INFORMATION AVAILABLE}

This information is available free of charge via the Internet at http: //pubs.acs.org.

\section{REFERENCES}

(1) Olivier, J. G. J.; Bouwman, A.; Berdowski, J.; Veldt, C.; Bloos, J.; Visschedijk, A.; Zandveld, P.; Haverlag, J. Description of EDGAR Version 2.0: A set of global emission inventories of greenhouse gases and ozone-depleting substances for all anthropogenic and most natural sources on a per country basis and on 1 degree $x$ 1 degree grid; National Institute of Public Health and the Environment: Bilthoven, The Netherlands, 1996. 
(2) Devinny, J. S.; Deshusses, M. A.; Webster, T. S. Biofiltration for Air Pollution Control. CRC Press: Boca Raton, 1998.

(3) Kim, S.; Deshusses, M. A. Understanding the limits of $\mathrm{H}_{2} \mathrm{~S}$ degrading biotrickling filters using a differential biotrickling filter. Chem. Eng. J. 2005, 113, 119.

(4) Kim, S.; Deshusses, M. A. Determination of mass transfer coefficients for packing materials used in biofilters and biotrickling filters for air pollution control - 1 . Experimental results. Chem. Eng. Sci. 2008, 63, 841.

(5) Kim, S.; Deshusses, M. A. Determination of mass transfer coefficients for packing materials used in biofilters and biotrickling filters for air pollution control - 2 : Development of mass transfer coefficients correlations. Chem. Eng. Sci. 2008, 63, 856.

(6) González-Sánchez, A.; Tomas, M.; Dorado, A. D.; Gamisans, X.; Guisasola, A.; Lafuente, J.; Gabriel, D. Development of a kinetic model for elemental sulfur and sulfate formation from the autotrophic sulfide oxidation using respirometric techniques. Water Sci. Technol. 2009, 59, 1323.

(7) Diks, R. M. M.; Ottengraf, S. P. P. Verification studies of a simplified model for the removal of dichloromethane from waste gases using a biological trickling filter. Part 1. Bioprocess Eng. 1991, 6, 93.

(8) Diks, R. M. M.; Ottengraf, S. P. P. Verification studies of a simplified model for the removal of dichloromethane from waste gases using a biological trickling filter. Part 2. Bioprocess Eng. 1991, 6, 131.

(9) Lebrero, R.; Rodríguez, E.; Pérez, R.; García-Encina, P. A.; Muñoz, R. Abatement of odorant compounds in one-and two-phase biotrickling filters under steady and transient conditions. Appl. Microbiol. Biotechnol. 2013, 97, 4627.

(10) Di Felice, R.; Gibilaro, L. Wall effects for the pressure drop in fixed beds. Chem. Eng. Sci. 2004, 59, 3037.

(11) Mulcahy, L. T.; Shieh, W. K. Fluidization and reactor biomass characteristics of the denitrification fluidized bed biofilm reactor. Water Res. 1987, 21, 451.

(12) Lobo, R.; Revah, S.; Viveros-Garcia, T. An analysis of a trickle-bed bioreactor: Carbon disulfide removal. Biotechnol. Bioeng. 1999, 63, 98.

(13) Arellano-García, L.; Dorado, A.; Morales-Guadarrama, A.; Sacristan, E.; Gamisans, X.; Revah, S. Modeling the effects of biomass accumulation on the 
performance of a biotrickling filter packed with PUF support for the alkaline biotreatment of dimethyl disulfide vapors in air. Appl. Microbiol. Biotechnol. 2014, 1.

(14) Arellano-García, L.; González-Sánchez, A.; Van Langenhove, H.; Kumar, A.; Revah, S. Removal of odorant dimethyl disulfide under alkaline and neutral conditions in biotrickling filters. Water Sci. Technol. 2012, 66, 1641.

(15) González-Sánchez, A.; Revah, S.; Deshusses, M. A. Alkaline biofiltration of $\mathrm{H}_{2} \mathrm{~S}$ odors. Environ. Sci. Technol. 2008, 42, 7398.

(16) García-Peña, E.; Hernández, S.; Favela-Torres, E.; Auria, R.; Revah, S. Toluene biofiltration by the fungus Scedosporium apiospermum TB1. Biotechnol. Bioeng. 2001, 76, 61.

(17) García-Peña, I.; Hernández, S.; Auria, R.; Revah, S. Correlation of biological activity and reactor performance in biofiltration of toluene with the fungus Paecilomyces variotii CBS115145. Appl. Environ. Microbiol. 2005, 71, 4280.

(18) Trejo-Aguilar, G.; Revah, S.; Lobo-Oehmichen, R. Hydrodynamic characterization of a trickle bed air biofilter. Chem. Eng. J. 2005, 113, 145.

(19) Amanullah, M.; Farooq, S.; Viswanathan, S. Modeling and simulation of a biofilter. Ind. Eng. Chem. Res. 1999, 38, 2765.

(20) Salehahmadi, R.; Halladj, R.; Zamir, S. M. Unsteady-state mathematical modeling of a fungal biofilter treating hexane vapor at different operating temperatures. Ind. Eng. Chem. Res. 2012, 51, 2388.

(21) Woertz, J.; Kinney, K.; Mclntosh, N.; Szaniszlo, P. Removal of toluene in a vapor phase bioreactor containing a strain of the dimorphic black yeast Exophiala lecanii corni. Biotechnol. Bioeng. 2001, 75, 550.

(22) Baquerizo, G.; Maestre, J. P.; Sakuma, T.; Deshusses, M. A.; Gamisans, X.; Gabriel, D.; Lafuente, J. A detailed model of a biofilter for ammonia removal: model parameters analysis and model validation. Chem. Eng. J. 2005, 113, 205.

(23) Kim, S.; Deshusses, M. A. Development and experimental validation of a conceptual model for biotrickling filtration of $\mathrm{H}_{2} \mathrm{~S}$. Environ. Prog. 2003, 22, 119.

(24) Dorado, A. D.; Baquerizo, G.; Maestre, J. P.; Gamisans, X.; Gabriel, D.; Lafuente, J. Modeling of a bacterial and fungal biofilter applied to toluene abatement: Kinetic parameters estimation and model validation. Chem. Eng. J. 2008, 140, 52.

(25) Onda, K.; Takeuchi, H.; Okumoto, Y. Mass transfer coefficients between gas 
and liquid phases in packed columns. J. Chem. Eng. Japan 1968, 1, 56.

(26) Lomans, B. P.; Pol, A.; den Camp, H. Microbial cycling of volatile organic sulfur compounds in anoxic environments. Water Sci. Technol. 2002, 45, 55.

(27) Stefess, G.; Torremans, R.; De Schrijver, R.; Robertson, L.; Kuenen, J. Quantitative measurement of sulphur formation by steady-state and transient-state continuous cultures of autotrophic Thiobacillus species. Appl. Microbiol. Biotechnol. 1996, 45, 169.

(28) Bosch, P. L. F. v. d.; Fortuny-Picornell, M.; Janssen, A. J. H. Effects of Methanethiol on the Biological Oxidation of Sulfide at Natron-Alkaline Conditions. Environ. Sci. Technol. 2008, 43, 453.

(29) Arellano-García, L.; González-Sánchez, A.; Baquerizo, G.; HernándezJimenez, S.; Revah, S. Treatment of carbon disulfide and ethanethiol vapors in alkaline biotrickling filters using an alkaliphilic sulfo-oxidizing bacterial consortium. $J$. Chem. Technol. Biotechnol. 2010, 85, 328.

(30) Andrews, G. Effectiveness factors for bioparticles with Monod kinetics. Chem. Eng. J. 1988, 37, B31.

(31) Fogler, H. S. Elements of Chemical Reaction Engineering. Prentice-Hall, Inc.: New Jersey, 2005.

(32) Bailey, J. E.; Ollis, D. F. Biochemical Engineering Fundamentals. McGraw-Hill: New York, 1976.

(33) Deshusses, M. A.; Hamer, G.; Dunn, I. J. Behavior of biofilters for waste air biotreatment. 1. Dynamic model development. Environ. Sci. Technol. 1995, 29, 1048.

(34) De Beer, D.; Stoodley, P.; Roe, F.; Lewandowski, Z. Effects of biofilm structures on oxygen distribution and mass transport. Biotechnol. Bioeng. 1994, 43, 1131.

(35) Smith, N. A.; Kelly, D. P. Isolation and physiological characterization of autotrophic sulfur bacteria oxidizing dimethyl disulfide as sole source of energy. $J$. Gen. Microbiol. 1988, 134, 1407.

(36) Smith, N. A.; Kelly, D. P. Mechanism of oxidation of dimethyl disulphide by Thiobacillus thioparus strain E6. J. Gen. Microbiol. 1988, 134, 3031.

(37) Ramírez, M.; Fernández, M.; Granada, C.; Le Borgne, S.; Gómez, J. M.; Cantero, D. Biofiltration of reduced sulphur compounds and community analysis of 
sulphur-oxidizing bacteria. Bioresour. Technol. 2011, 102, 4047.

(38) Wan, S.; Li, G.; An, T.; Guo, B. Co-treatment of single, binary and ternary mixture gas of ethanethiol, dimethyl disulfide and thioanisole in a biotrickling filter seeded with Lysinibacillus sphaericus RG-1. J. Hazard. Mater. 2011, 186, 1050.

(39) Weber, F. J.; Hage, K. C.; De Bont, J. Growth of the fungus Cladosporium sphaerospermum with toluene as the sole carbon and energy source. Appl. Environ. Microbiol. 1995, 61, 3562.

(40) Dorado, A. D.; Lafuente, J.; Gabriel, D.; Gamisans, X. Biomass accumulation in a biofilter treating toluene at high loads - Part 2: Model development, calibration and validation. Chem. Eng. J. 2012, 209, 670.

(41) Vergara Fernández, A.; Hernández, S.; Revah, S. Phenomenological model of fungal biofilters for the abatement of hydrophobic VOCs. Biotechnol. Bioeng. 2008, $101,1182$.

\section{LIST OF SYMBOLS}

$a=\quad$ specific surface area (surface area per unit volume of biofilter bed), $\mathrm{m}^{2} \mathrm{~m}^{-3}$

$A=$ cross section area of the HR, $\mathrm{m}^{2}$

$A_{W}=$ wet area of packing per volume of bed, $\mathrm{m}^{2} \mathrm{~m}^{-3}$ bed

$a_{b}=$ area of the biofilm per volume of bed, $\mathrm{m}^{2} \mathrm{~m}^{-3}$ bed

$A_{\text {sup }}=$ area of packing per volume of bed, $\mathrm{m}^{2} \mathrm{~m}^{-3}$ bed

$a_{g_{-}}=$interfacial area gas-liquid per volume of bed, $\mathrm{m}^{2} \mathrm{~m}^{-3}$ bed

$a_{g_{-} b}=$ interfacial area gas-biofilm per volume of bed, $\mathrm{m}^{2} \mathrm{~m}^{-3}$ bed

$a_{I} b=$ interfacial area liquid-biofilm per volume of bed, $\mathrm{m}^{2} \mathrm{~m}^{-3}$ bed

$C_{b_{-} w, i}=\quad$ concentrations of component $i$ in the biofilm, $\mathrm{g} \mathrm{m}^{-3}$

$C_{b_{-} w, i}=\quad$ concentrations of component $i$ in the wetted biofilm, $\mathrm{g} \mathrm{m}^{-3}$

$C_{b \_n w, i}=\quad$ concentrations of component $i$ in the non-wetted biofilm, $\mathrm{g} \mathrm{m}^{-3}$

$C_{g, i}=$ concentration of component $i$ in the gas phase, $\mathrm{g} \mathrm{m}^{-3}$

$C_{l, i},=$ concentrations of component $i$ in the liquid phase, $\mathrm{g} \mathrm{m}^{-3}$

$C_{l, i}^{*}=$ concentration of component $i$ at the liquid interface, $\mathrm{g} \mathrm{m}^{-3}$

$D_{\text {eff,i }}=$ diffusion coefficient of component $i$ in the biofilm, $\mathrm{m}^{2} \mathrm{~h}^{-1}$

$\mathrm{He}_{i}=$ gas/liquid partition coefficient of component $i$ in a air/aqueous system

$K_{S, i}=$ half saturation constant for component $i, \mathrm{~g} \mathrm{~m}^{-3}$

$K_{L}=$ mass transfer coefficient for component $\mathrm{i}, \mathrm{m}^{-1} \mathrm{~h}^{-1}$

$K_{L} a_{g-l}=$ global mass transfer coefficient, $\mathrm{h}^{-1}$ 
$K_{G a g-b}=$ gaseous global mass transfer coefficient, $\mathrm{h}^{-1}$

$N_{l-b, i}=$ mass flux of component $i$ from the liquid phase to the biofilm, $\mathrm{g} \mathrm{m}^{-2} \mathrm{~h}^{-1}$

$N_{g-b, i}=$ mass flux of component $i$ from the gas phase to the biofilm, $\mathrm{g} \mathrm{m}^{-2} \mathrm{~h}^{-1}$

$N_{g-1, i}=$ mass flux of component $i$ from the gas phase to the liquid phase, $\mathrm{g} \mathrm{m}^{-2} \mathrm{~h}^{-1}$

OUR $\max =$ maximum Oxygen Uptake Rate $\left(\mathrm{g} \mathrm{m}^{-3} \mathrm{~h}^{-1}\right)$

$Q_{g}=$ gaseous volumetric flow rate, $\mathrm{m}^{3} \mathrm{~h}^{-1}$

$Q_{l}=$ liquid volumetric flow rate, $\mathrm{m}^{3} \mathrm{~h}^{-1}$

$r_{b, i}=$ consumption rates of component $i$ in the biofilm $\left(\mathrm{g} \mathrm{m}^{-3} \mathrm{~h}^{-1}\right)$

$R_{\text {max }}=$ maximum consumption rate of DMDS $\left(\mathrm{g} \mathrm{m}^{-3} \mathrm{~h}^{-1}\right)$

$t=$ time, $\mathrm{h}$

$U_{L z}=$ liquid linear velocity $\left(\mathrm{m} \mathrm{h}^{-1}\right)$

$U_{G z}=$ gas linear velocity $\left(\mathrm{m} \mathrm{h}^{-1}\right)$

$V_{\text {bed }}=$ total $\mathrm{HR}$ volume $\mathrm{m}^{3}$

$V_{g}=$ gaseous volume, $\mathrm{m}^{3}$

$V_{l}=$ liquid volume, $\mathrm{m}^{3}$

$x=$ position along the biofilm thickness, $\mathrm{m}$

$X_{b}=$ dry biomass concentration, $\mathrm{gdw}_{\mathrm{dw}}^{-3}{ }_{\text {bed }}$

$Y_{X / O 2}=$ biomass yield coefficient for oxygen, $g$ biomass $(g \text { oxygen })^{-1}$

$Y_{X / P}=$ biomass yield coefficient for pollutant, $g$ biomass $(g \text { oxygen })^{-1}$

$z=$ axial position along the biofilter height, $m$

Subscripts

$\mathrm{BOH}=$ Benzyl alcohol

$i=$ component (oxygen, DMDS, toluene, methyl mercaptan)

$n w=$ non-wetted biofilm

$P=$ Pollutant

$w=$ wetted biofilm

Superscripts

bottom $=$ bottom of packed bed

ext $=\quad$ external gas flow

in $=\quad$ inlet

lower $=\quad$ gaseous lower section of $\mathrm{HR}$

rec $=\quad$ recirculation flow (gas or liquid)

res $=\quad$ reservoir

sup $=\quad$ superficial available area of packing material

Greek Letters 
$\alpha=\quad$ wetted fraction of the total area of packed bed

$\beta=\quad$ fraction of the total area of packed bed covered with biofilm

$\delta=$ biofilm thickness, $\mathrm{m}$

biofilm=Biofilm density, $\mathrm{kg} \mathrm{m}^{-3}$

$\varepsilon_{l}=\quad$ volume fraction of the HR occupied by the liquid in the packed bed, $\mathrm{m}^{3} \mathrm{~m}^{-3}$

$\varepsilon_{S}=$ volume fraction of the HR occupied by the solid in the packed bed, $\mathrm{m}^{3} \mathrm{~m}^{-3}$

$\varepsilon_{g}=$ volume fraction of the HR occupied by the gas in the packed bed, $\mathrm{m}^{3} \mathrm{~m}^{-3}$

$\varepsilon_{b}=$ volume fraction of the HR occupied by the biofilm in the packed bed, $\mathrm{m}^{3} \mathrm{~m}^{-3}$

$\mu_{\max }=$ maximum specific growth rate, $\mathrm{h}^{-1}$

$\eta=$ effectiveness biofilm factor,

$\omega=$ wet biomass weight ratio,

\section{Figure captions}

Figure 1. Heterogeneous Respirometer schematics. (a) BF configuration; (b) BTF configuration.

Figure 2. Diagram of the phases and fluxes considered in the mathematical model for the HR operated as a BTF. ( $\alpha$ ) Gas-liquid and ( $\beta$ ) liquid-biofilm fractional areas. For fungal biofiltration $\alpha=0$.

Figure 3. Batch respirometry performance using the HR as a BTF, with DMDS as substrate and the ASOC colonized polyurethane foam as packing. Linear velocities for gas and liquid were $89 \mathrm{~m} \mathrm{~h}^{-1}$ and $14.8 \mathrm{~m} \mathrm{~h}^{-1}$ respectively. (a) Gaseous and dissolved oxygen profiles; (b) Dissolved DMDS profile.

Figure 4. Fluxes (a) and volumetric mass transfer rates (b) through the three interfaces considered in the HR model, operated as BTF for the consumption of DMDS.

Figure 5. Batch respirometry performance using the HR as a BF, with toluene as substrate and the fungal colonized polyurethane foam as packing. Linear velocity for gas was $35 \mathrm{~m} \mathrm{~h}^{-1}$. (a) Gaseous oxygen and toluene profiles; (b) Gaseous carbon dioxide profile.

Figure 6. Estimated biofilm effectiveness factor during the simulated respirometry assays for (a) DMDS and (b) toluene elimination. Criteria for regime control from ${ }^{31}$, 30,32 . 